\title{
Review Article \\ Mesenchymal Stem Cells and COVID-19: Cure, Prevention, and Vaccination
}

\author{
Mehrdad Afarid (iD) and Fatemeh Sanie-Jahromi \\ Poostchi Ophthalmology Research Center, Department of Ophthalmology, School of Medicine, Shiraz University of Medical Sciences, \\ Shiraz, Iran \\ Correspondence should be addressed to Fatemeh Sanie-Jahromi; fsanie@sums.ac.ir
}

Received 4 December 2020; Revised 26 February 2021; Accepted 21 April 2021; Published 7 May 2021

Academic Editor: Marta Baiocchi

Copyright (c) 2021 Mehrdad Afarid and Fatemeh Sanie-Jahromi. This is an open access article distributed under the Creative Commons Attribution License, which permits unrestricted use, distribution, and reproduction in any medium, provided the original work is properly cited.

\begin{abstract}
COVID-19 disease has been a global health problem since late 2019. There are many concerns about the rapid spread of this disease, and yet, there is no approved treatment for COVID-19. Several biological interventions have been under study recently to investigate efficient treatment for this viral disease. Besides, many efforts have been made to find a safe way to prevent and vaccinate people against COVID-19 disease. In severe cases, patients suffer from acute respiratory distress syndrome usually associated with an increased level of inflammatory cytokines, called a cytokine storm. It seems that reequilibrating the hyperinflammatory response of the host immune system and regeneration of damaged cells could be the main way to manage the disease. Mesenchymal stem cells (MSCs) have been recently under investigation in this regard, and the achieved clinical outcomes show promising evidence for stem cell-based therapy of COVID-19. MSCs are known for their potential for immunomodulation, defense against virus infection, and tissue regeneration. MSCs are a newly emerged platform for designing vaccines and show promising evidence in this area. In the present study, we provided a thorough research study on the most recent clinical studies based on stem cells in the treatment of COVID-19 while introducing stem cell exclusivities for use as an immune disorder or lung cell therapy and its potential application for protection and vaccination against COVID-19.
\end{abstract}

\section{Introduction}

New coronavirus (COVID-19) disease has been a pandemic catastrophe since January 2020, when the World Health Organization (WHO) declared COVID-19 as a global health emergency. Severe acute respiratory syndrome coronavirus 2 (SARS-CoV-2) has a 27-32 kb nucleotide genome composed of a single-stranded RNA. The 8 nonstructural and the 4 structural proteins (including membrane $(\mathrm{M})$, nucleocapsid $(\mathrm{N})$, envelope $(\mathrm{E})$, and spike $(\mathrm{S})$ ) are encoded by the virus genome $[1,2]$. This virus is transmitted very quickly around the world and has affected millions of people so far. Infection with this virus mostly results in either none or mild symptoms (flu-like signs), is self-limited, and needs no preferential treatment. However, 2-6\% of the patients demonstrate acute respiratory distress syndrome (ARDS), lung fibrosis, and multiorgan failure that might lead to death [3]. The mortality rate of COVID-19 is reported to vary in different ages and nations [4]. Due to the highly contagious quality of the SARS-CoV-2 virus, it is estimated that many people may die from COVID-19 infection all over the world. Many preventive and treatment medications have been recommended since the diagnosis of this virus, and lots of research are under consideration to provide an approved medication. From a pathophysiological point of view, COVID-19 is usually associated with elevated levels of inflammatory cytokines including interleukin- (IL-) 2, IL-6, IL-7, granulocyte colonystimulating factor (GSCF), interferon-inducible protein 10 (IP10), monocyte chemotactic protein 1 (MCP1), macrophage inflammatory protein $1 \mathrm{~A}$ (MIP1A), and TNF- $\alpha[4$, 5]. This condition is called cytokine storm. Besides, COVID-19 in severe cases is associated with ARDS and the damage to alveolar epithelial and endothelial cells. It seems that antiviral, anti-inflammatory, and cell regenerative therapies as well as supportive care during the period of the disease are the main treatments for COVID-19 [6]. A review of 
recent studies showed that biological interventions are promising for the management of inflammatory responses and tissue treatment of degenerative diseases. Of these, mesenchymal stem cell (MSC) therapy has found a special place in the therapeutic research of COVID-19 [7]. MSCbased treatments have been applied in several autoimmune disorders successfully and are approved to be a safe treatment $[8,9]$. It seems that MSCs can exert a profound effect on COVID-19 treatment relying on its immunomodulatory effect and regenerating potential. The present study focuses on stem cell characteristics and introduces a brief review on the most recent stem cell-based clinical studies for the treatment of COVID-19. We also focused on the molecular aspects of MSCs, their unique features to be used as a preventive factor against COVID-19, and vaccine design.

This study represents the results from a thorough survey in several databases of MEDLINE/PubMed, Web of Science, Embase, and Google Scholar regarding the terms "COVID19 " and "stem cell" from 19 October 2020. We extracted clinical trial registries using the WHO International Clinical Trials Registry Platform (ICTRP) and clinicaltrials.gov to provide any stem cell-based intervention for COVID-19 treatment from December 2019 to October 2020. Both clinical trial and experimental studies on the effect of stem cellbased strategies for COVID-19 treatment were included in this study. Besides, the most relevant documents considering "stem cell biology," "immunomodulatory effects of stem cells," and "regenerative and anti-apoptotic effects of stem cells" were also included for the interpretation of documented results.

\section{MSCs for Treatment of Lung Diseases and Immune Disorders}

One of the main features of ARDS is the disruption of the alveolar-capillary membrane and apoptosis of alveolar epithelial and endothelial cells. Apoptotic cells attract inflammatory cells and lead to lung tissue regeneration. Based on recent in vivo studies, MSCs can inhibit from apoptosis of the alveolar epithelial cells and endothelial cells due to the secretion of growth factors such as keratinocyte growth factor (KGF), angiopoietin-1 (Ang1), and hepatocyte growth factor (HGF) and reduction of tumor necrosis factor- $\alpha$ $(\mathrm{TNF}-\alpha)$ [10-13]. Due to the decreased pulmonary permeability and increased alveolar edema and intrapulmonary shunting, ARDS is commonly associated with hypoxemia [14]. MSCs can be stimulated in response to the hypoxic stress from the lung tissue [15]. It has been demonstrated that in hypoxic conditions, the secretome of adipose-derived MSCs is enriched with angiogenic factors and improves angiogenesis in an in vivo mouse model [16]. Elevated secretion of Ang1 and KGF from bone marrow-derived MSCs was recently reported to attenuate inflammation and inhibit alveolar epithelial cells from apoptosis [11]. It seems that MSCs are promising candidates for airway treatment considering their angiogenic properties and their ability to reduce alveolar cell apoptosis. According to previous studies, MSCs have been tested in animal models and clinical trials for the treatment of lung diseases and immune disorders. It has been demonstrated that MSCs can exert an immunomodulatory effect on mice with LPS-mediated lung injury through stanniocalcin-2 protein [17]. MSC therapy is now an approved medication for the treatment of several immune diseases including multiple sclerosis and Crohn's disease [8]. Moreover, promising results are available for MSCs application in animal models for the treatment of lung disease (such as idiopathic pulmonary fibrosis, chronic obstructive bronchiolitis, and bronchopulmonary dysplasia) [18-20].

2.1. Clinical Application of MSCs for COVID-19 Treatment. According to recent studies, MSC therapy seems to be an innovative treatment for COVID-19, as it involves lung tissue and is associated with inflammatory responses. Stem cells are considered a choice in the treatment of diseases with high morbidity rates, based on FDA regulations [21]. By the time of preparing this paper, 88 stem cell-based clinical trials were registered in clinicaltrials.gov and ICTRP portal for treatment of COVID-19. Different sources have been used for extraction and expansion of MSCs in these trials according to the details provided by clinicaltrials.gov and ICTRP portal. Most of these clinical trials were conducted in China, and the outcomes showed the safety of stem cell-based treatments to cure severe cases of COVID-19. Stem cell-based therapies for COVID-19 are mainly administered as an intravenous injection (IV) of MSCs suspension; however, the application of extracellular vesicles secreted by stem cells has also been reported.

2.2. IV of MSCs. The therapeutic effect of MSCs in the treatment of COVID-19 has been evaluated in several clinical trials in recent months considering its safety and efficacy. A brief review of registered clinical trials in clinicaltrials.gov and ICTRP portal is presented in Table 1. As shown in Table 1, umbilical cord-derived MSCs are reported to be the most used stem cells, and the main route of administration is IV. MSCs used for these trials were mostly extracted from autologous or allogenic tissue sources and expanded in clinical-grade clean rooms. After the assessment of specific markers (positive for surface markers CD 73, CD 90, and CD105; negative for surface markers CD11b, CD14, CD19, CD34, CD45, CD79a, and HLA-DR) and confirmation of noncontamination, the cells were usually suspended in a standard buffer (mostly normal saline) for infusion into the patients. The dose of suspended cells $/ \mathrm{ml}$ or cells $/ \mathrm{kg}$, the number of injections, and the time of intervals between injections vary in different studies (see Table 1). Although many of the registered studies are still recruiting, the the primary clinical outcomes clinical outcomes suggest that MSC therapy is promising for COVID-19 treatment, particularly in severe cases (see below).

2.3. Conditioned Medium and Extracellular Vesicles Derived from Stem Cells. Extracellular vesicles (EVs) consist of exosomes and microvesicles with a diameter of 0.03 to $1 \mu \mathrm{m}$, secreted by all cell types. EV contains macromolecules secreted by the cell source and is the main factor in intercellular communication through paracrine secretion [22, 23]. The effect of MSC-EV on the treatment of viral and bacterial 
TABLE 1: A brief review of recent clinical trials using stem cell-based therapy for treatment of COVID-19.

\begin{tabular}{|c|c|c|c|}
\hline \multicolumn{4}{|c|}{ Stem cell source: umbilical cord-derived stem cells (UC, WJ, placental-MSCs) } \\
\hline$N$ (age) & Route of administration & $S$ & Clinical trial ID \\
\hline $20(18-70)$ & $3 \times \operatorname{IV}\left(3 \times 10^{7}\right.$ cells/infusion at $\left.\mathrm{d} 0,3,6\right)$ & $\mathrm{R}$ & NCT04252118 (China) \\
\hline $30(\geq 18)$ & $3 \times$ IV (details not specified) & $\mathrm{R}$ & ChiCTR2000030866 (China) \\
\hline $20(16-75)$ & $3 \times$ IV $\left(2\right.$ doses: $\left(10^{6}\right.$ cells $/ \mathrm{kg}$ in $\left.1.25 \mathrm{ml}\right)$ and $\left(2 \times 10^{6}\right.$ cells $/ \mathrm{kg}$ in $\left.\left.2.5 \mathrm{ml}\right)\right)$ & $\mathrm{R}$ & ChiCTR2000030835 (China) \\
\hline $16(18-80)$ & $4 \times \operatorname{IV}\left(3.3 \times 10^{7} / 50 \mathrm{ml} / \mathrm{bag}, 3\right.$ bags each time at days $1,3,5$, and 7$)$ & $\mathrm{R}$ & NCT04269525 (China) \\
\hline $9(18-75)$ & IV (details not specified) & $\mathrm{R}$ & ChiCTR2000030300 (China) \\
\hline $48(18-65)$ & $4 \times \operatorname{IV}\left(5 \times 10^{6} / \mathrm{kg}\right.$ at days $1,3,5$, and 7$)$ & NR & NCT04273646 (China) \\
\hline $60(18-70)$ & (details not specified) & NR & ChiCTR2000030173 (China) \\
\hline $60(16-75)$ & IV (details not specified) & NR & ChiCTR2000030138 (China) \\
\hline $16(18-75)$ & IV (comparison of different doses, details not specified) & $\mathrm{R}$ & ChiCTR2000030116 (China) \\
\hline $60(\geq 18)$ & IV (details not specified) & NR & ChiCTR2000029816 (China) \\
\hline$[17-74]$ & $4 \times \operatorname{IV}\left(0.5 \times 10^{6} / \mathrm{kg}\right.$ in $\left.100 \mathrm{ml}\right)$ & $\mathrm{W}$ & NCT04293692 (China) \\
\hline $10(18-95)$ & $3 \times \operatorname{IV}\left(0.5-1 \times 10^{6}\right.$ at days 1,3 , and 6$)$ & NR & IRCT20140528017891N8 (Iran) \\
\hline $40(\geq 18)$ & $1 \times$ IV (details not specified) & $\mathrm{C}$ & NCT04573270 (USA) \\
\hline $70(\geq 18)$ & IV (at day 1 , second infusion at day 7 according to physician discretion) & $\mathrm{R}$ & NCT04565665 (USA) \\
\hline $30(18-70)$ & $\operatorname{IV}\left(1 \times 10^{6} / \mathrm{kg}\right)$ & NR & IRCT20200426047206N2 (Iran) \\
\hline $20(18-70)$ & $3 \times \operatorname{IV}\left(1 \times 10^{6} / \mathrm{kg}\right.$ at days 1,3 , and 6$)$ & $\mathrm{R}$ & IRCT20160809029275N1 (Iran) \\
\hline $30(18-79)$ & IV $\left(1 \times 10^{6}\right.$ cells $\left./ \mathrm{kg}\right)$ & NR & NCT04429763 \\
\hline $30(18-75)$ & $\begin{array}{c}\text { IV }\left(1 \times 10^{6} \text { cell } / \mathrm{kg} \text { in } 100 \mathrm{ml} \text { of NS, second infusion at } \mathrm{d} 7 \text { according }\right. \\
\text { to physician discretion) }\end{array}$ & $\mathrm{R}$ & NCT04339660 (China) \\
\hline $20(30-70)$ & $3 \times \operatorname{IV}\left(5 \times 10^{5}\right.$ cell $/ \mathrm{kg}$ at $\left.\mathrm{d} 1,3,5\right)$ & $\mathrm{R}$ & NCT04437823 (Pakistan) \\
\hline $21(\geq 18)$ & $2 \times \operatorname{IV}\left(100 \times 10^{6} \mathrm{cell} / \mathrm{kg}\right.$ at days 0 and 3$)$ & NR & NCT04490486 (USA) \\
\hline $60(18-70)$ & $4 \times \operatorname{IV}\left(10^{6}\right.$ cell $/ \mathrm{kg} /$ time every 4 days $)$ & NR & NCT04371601 (China) \\
\hline $60(\geq 18)$ & 1 or $2 \times$ IV by $48 \mathrm{~h}$ interval $\left(10^{6}\right.$ cell/dose in NS) & $\mathrm{R}$ & NCT04494386 (USA) \\
\hline $40(18-95)$ & $1 \times \mathrm{IV}\left(1 \times 10^{6} / \mathrm{kg}\right.$ in $100 \mathrm{ml}$ of NS $)$ & $\mathrm{R}$ & NCT04457609 (Indonesia) \\
\hline $40(18-80)$ & IV $\left(1 \times 10^{6}\right.$ cell $/ \mathrm{kg}$ in $\left.40 \mathrm{ml}\right)$ & $\mathrm{R}$ & ChiCTR2000030088 (China) \\
\hline $5(\geq 18)$ & $3 \times \operatorname{IV}\left(10^{6}\right.$ cell $/ \mathrm{kg}$ in $25 \mathrm{ml}$ every 3 days $)$ & $\mathrm{R}$ & NCT04313322 (Jordan) \\
\hline $40(\geq 18)$ & $3 \times \operatorname{IV}\left(1 \times 10^{6}\right.$ cell $/ \mathrm{kg}$ in a $150 \mathrm{ml}$, at days 1,3 , and 5$)$ & $\mathrm{R}$ & NCT04333368 (France) \\
\hline $20(18-65)$ & IV ( 2 doses: $\left(10^{6}\right.$ cells $/ \mathrm{kg}$ in $\left.1.25 \mathrm{ml}\right)$ and $\left(2 \times 10^{6}\right.$ cells $/ \mathrm{kg}$ in $\left.2.5 \mathrm{ml}\right)$ at days 1 and & NR & CTRI/2020/08/027043 (India) \\
\hline $20(18-65)$ & $1 \times \operatorname{IV}\left(3\right.$ doses: $\left(100 \times 10^{6}\right.$ cells $( \pm 10 \%)$ at days 0,2 , and 4$)$ & $\mathrm{R}$ & IRCT20200413047063N1 (Iran) \\
\hline 6 (no limit) & $3 \times$ IV $\left(1 \times 10^{6}\right.$ cells $/ \mathrm{kg}$, once every $3-4$ days during a 14 -day period $)$ & $\mathrm{R}$ & IRCT20200418047121N2 (Iran) \\
\hline $90(18-85)$ & $\operatorname{IV}\left(0.5-2 \times 10^{6}\right.$ cell $/ \mathrm{kg}$, at days 1,3 , and 6$)$ & $\mathrm{R}$ & IRCT20200421047150N1 (Iran) \\
\hline $40(18-80)$ & $\operatorname{IV}\left(50 \times 10^{6}\right)$ & NR & NCT04390152 (Colombia) \\
\hline $9(\geq 18)$ & $1 \times \operatorname{IV}\left(1 \times 10^{8}\right.$ cells $)$ & NR & NCT04456361 (Mexico) \\
\hline $30(18-75)$ & $1 \times \mathrm{IV}(1 \times 108$ cells/kg at days 1 and 3$)$ & $\mathrm{R}$ & NCT04390139 (Spain) \\
\hline $24(\geq 18)$ & $\operatorname{IV}\left(100 \times 10^{6}\right.$ cells $)$ & NR & NCT04355728 (USA) \\
\hline \multicolumn{4}{|c|}{ Stem cell source: BM-MSCs } \\
\hline$N$ (age) & Route of administration & S & Clinical trial ID \\
\hline $20(18-75)$ & IV $\left(1 \times 10^{6} / \mathrm{kg}\right.$ at day 1$)$ & NR & NCT04346368 (China) \\
\hline $20(\geq 10)$ & $\begin{array}{l}\text { IV }\left(2 \times 10^{6} \text { cells } / \mathrm{kg} \text { at day } 1 \text {, second infusion at day } 7 \text { according }\right. \\
\text { to physician discretion })\end{array}$ & $\mathrm{R}$ & NCT04444271 (Pakistan) \\
\hline $40(\geq 18)$ & IV (details not specified) & NR & NCT04377334 (Germany) \\
\hline $45(18-80)$ & IV (details not specified) & $\mathrm{R}$ & NCT04397796 (USA) \\
\hline $9(18-65)$ & $1 \times \operatorname{IV}\left(2\right.$ doses: $\left(1 \times 10^{6}\right.$ cells $\left./ \mathrm{kg}\right)$ and $\left(1 \times 10^{6}\right.$ cells $\left.\left./ \mathrm{kg}\right)\right)$ & $\mathrm{R}$ & NCT04447833 (Sweden) \\
\hline \multicolumn{4}{|c|}{ Stem cell source: Ad-MSCs } \\
\hline$N$ (age) & Route of administration & S & Clinical trial ID \\
\hline $26(18-80)$ & IV $\left(80 \times 10^{6}\right.$ cells $)$ & $\mathrm{R}$ & NCT04366323 (Spain) \\
\hline
\end{tabular}


TABle 1: Continued.

\begin{tabular}{|c|c|c|c|}
\hline $100(\geq 18)$ & IV ( 2 serial doses of $1.5 \times 10^{6}$ cells $/ \mathrm{kg}$ ) & NR & NCT04348461 \\
\hline $20(18-90)$ & IV $\left(5 \times 10^{5}\right.$ cells $)$ & NR & NCT04352803 \\
\hline $10(19-80)$ & (details not specified) & NR & NCT04527224 \\
\hline $6(\geq 20)$ & $4 \times \mathrm{IV}\left(1 \times 10^{8}\right.$ cells, once a week $)$ & NR & JPRN-JapicCTI-205416 (Japan) \\
\hline $0(18-80)$ & IV $\left(100 \times 10^{6}\right.$ cells in $\left.100 \mathrm{ml} \mathrm{NS}\right)$ & NR & NCT04341610 (Denmark) \\
\hline $56(\mathrm{NL})$ & $5 \times$ IV (details not specified) & $\mathrm{E}$ & NCT04349631 (USA) \\
\hline $100(\mathrm{NL})$ & $\begin{array}{c}5 \times \text { IV }\left(3 \text { doses: }\left(50 \times 10^{6} \text { cells }\right),\left(100 \times 10^{6} \text { cells }\right) \text {, and }\left(200 \times 10^{6} \text { cells }\right)\right. \\
\text { at weeks } 0,2,6,10 \text {, and } 14)\end{array}$ & $\mathrm{E}$ & NCT04348435 (United States) \\
\hline $20(18-80)$ & (details not specified) & NR & NCT04486001 (USA) \\
\hline $200(\geq 18)$ & IV $\left(200 \times 10^{6}\right.$ cells, every three days $)$ & NR & NCT04428801 \\
\hline $100(\mathrm{NL})$ & $4 \times \operatorname{IV}\left(100 \times 10^{6}\right.$ cells at days $0,3,7$, and 10$)$ & NR & NCT04362189 (USA) \\
\hline \multicolumn{4}{|c|}{ Stem cell source: Dp-MSCs } \\
\hline$N$ (age) & Route of administration & S & Clinical trial ID \\
\hline $24(18-75)$ & $3 \times \mathrm{IV}\left(10^{6} \mathrm{cell} / \mathrm{kg}\right.$ in $\left.50 \mathrm{ml} \mathrm{NS}\right)$ & NR & NCT04302519 (China) \\
\hline $20(18-65)$ & $3 \times \mathrm{IV}\left(3 \times 10^{7}\right.$ cells in $30 \mathrm{ml}$ at days 1,4 , and 7$)$ & $\mathrm{R}$ & NCT04336254(China) \\
\hline $20(18-65)$ & IV (details not specified) & NR & ChiCTR2000031319 (China) \\
\hline $10(18-95)$ & $1 \times \operatorname{IV}\left(40 \times 10^{6}\right.$ cells $)$ & $\mathrm{R}$ & IRCT20140911019125N6 (Iran) \\
\hline \multicolumn{4}{|c|}{ Stem cell source: not specified } \\
\hline$N$ (age) & Route of administration & S & Clinical trial ID \\
\hline $\begin{array}{l}120(18- \\
95)\end{array}$ & IV $\left(1 \times 10^{6}\right.$ cells $/ \mathrm{kg}$ in $100 \mathrm{ml}$ of NS $)$ & $\mathrm{R}$ & ChiCTR2000029990 (China) \\
\hline $100(18-75)$ & $3 \times \operatorname{IV}\left(4 \times 10^{7}\right.$ cells/time at days 0,3 , and 6$)$ & $\mathrm{C}$ & NCT04288102 (China) \\
\hline $120(18-95)$ & (details not specified) & $\mathrm{R}$ & ChiCTR2000029990 (China) \\
\hline $20(18-70)$ & $4 \times$ IV (details not specified) & $\mathrm{R}$ & ChiCTR2000030020 (China) \\
\hline $32(18-100)$ & IV (details not specified) & NR & ChiCTR2000030224 (China) \\
\hline $90(\geq 18)$ & IV ( 3 or 4 cycles of $2 \times 10^{7}$ cells at days $1,3,5$, and 7 ) & NR & NCT04315987 (Brazil) \\
\hline $9(18-70)$ & IV ( 3 doses: $3 \times 10^{6}, 5 \times 10^{6}$, and $10 \times 10^{6}$ cells $/ \mathrm{kg}$ ) & $\mathrm{R}$ & NCT04331613 (China) \\
\hline $200(18-80)$ & $3 \times$ IV (details not specified) & $\mathrm{R}$ & ChiCTR2000031430 (China) \\
\hline $36(18-90)$ & IV (details not specified) & $\mathrm{R}$ & ChiCTR2000031494 (China) \\
\hline $5(18-70)$ & $3 \times \operatorname{IV}\left(70 \times 10^{6}\right.$ cells at days 0,3 , and 6$)$ & NR & IRCT20200325046860N2 (Iran) \\
\hline $30(40-60)$ & IV $\left(3 \times 10^{6}\right.$ cells $/ \mathrm{kg}$ at days 0,3 , and 6$)$ & $\mathrm{R}$ & NCT04392778 (Turkey) \\
\hline $10(\geq 18)$ & $1 \times \operatorname{IV}\left(1 \times 10^{6}\right.$ cells $\left./ \mathrm{kg}\right)$ & $\mathrm{R}$ & NCT04416139 (Mexico) \\
\hline $6(18-70)$ & $3 \times \operatorname{IV}\left(200 \times 10^{6}( \pm 10 \%)\right.$ cells in $50 \mathrm{ml} \mathrm{NS}$ at days 0,2 , and 4$)$ & NR & IRCT20200217046526N1 (Iran) \\
\hline $300(\geq 18)$ & $\begin{array}{c}2 \times 10^{6} \text { cells } / \mathrm{kg} \text {, second infusion at } 4 \text { days following the first } \\
\text { infusion }( \pm 1 \text { day) }\end{array}$ & $\mathrm{R}$ & NCT04371393 (USA) \\
\hline $400(18-89)$ & IV (details not specified) & $\mathrm{R}$ & NCT04367077 (USA) \\
\hline $24(\geq 18)$ & IV $\left(2 \times 10^{6}\right.$ cells $/ \mathrm{kg}$ at days 1 and 3$)$ & $\mathrm{R}$ & NCT04537351 (Australia) \\
\hline $9(\geq 19)$ & IV $\left(2\right.$ doses: $\left(5 \times 10^{7}\right.$ cells $)$ and $\left(1 \times 10^{8}\right.$ cells $\left.)\right)$ & NR & NCT04535856 (Indonesia) \\
\hline \multicolumn{4}{|l|}{ MSC-EVs } \\
\hline$N$ (age) & Route of administration & S & Clinical trial ID \\
\hline $24(18-75)$ & $5 \times$ aerosol inhalation $\left(2 \times 10^{8} \mathrm{EV} / 3 \mathrm{ml}\right.$ at days $1,2,3,4$, and 5$)$ & $\mathrm{C}$ & NCT04276987 (China) \\
\hline $26(18-65)$ & Aerosol inhalation (details not specified) & NR & ChiCTR2000030261 (China) \\
\hline $64(\geq 70)$ & IV $(0.2 \mathrm{mg} / \mathrm{kg}$ in $15 \mathrm{ml}$ at days 1 and 3$)$ & $\mathrm{R}$ & ISRCTN33578935 (Germany) \\
\hline \multicolumn{4}{|c|}{ MSCs + MSC-EVs } \\
\hline$N$ (age) & Route of administration & $\mathrm{S}$ & Clinical trial ID \\
\hline $90(18-70)$ & $\begin{array}{l}\text { UC-MSCs and exosomes } \\
\text { IV }\left(5 \times 10^{7} \text { cells/time, } 1 \text { time/week, } 2 \text { times/course, a total of } 2 \text { courses; }\right. \\
\text { exosomes: } 180 \mathrm{mg} / \text { time, } 1 \text { time/day, } 7 \text { days/course, } 2 \text { courses in total })\end{array}$ & NR & ChiCTR2000030484 (China) \\
\hline
\end{tabular}


TABLE 1: Continued.

\begin{tabular}{|c|c|c|c|}
\hline $60(18-65)$ & $\begin{array}{c}\text { MSCs }+ \text { EVs } \\
2 \times \operatorname{IV}\left(3 \text { doses: } 100 \times 10^{6}( \pm 10 \%) \text { cells at days } 0 \text { and } 2\right) \\
2 \times \operatorname{IV}(\text { MSC-EVs at } \mathrm{d} 4,6)\end{array}$ & $\mathrm{R}$ & $\begin{array}{c}\text { NCT04366063 } \\
\text { (IRCT20200217046526N2) (Iran) }\end{array}$ \\
\hline \multicolumn{4}{|c|}{ Stem cell-based combination therapies } \\
\hline$N$ (age) & Route of administration & S & Clinical trial ID \\
\hline $70(18-75)$ & MSCs + ruxolitinib (details not specified) & $\mathrm{R}$ & ChiCTR2000029580 (China) \\
\hline $30(\geq 18)$ & UCB-MNC CM (details not specified) & NR & ChiCTR2000029569 (China) \\
\hline $75(\geq 16)$ & $\begin{array}{l}\text { UC-MSCs enriched with CD362 } \\
\text { IV (maximum tolerated dose from the phase } 1 \text { trial) }\end{array}$ & $\mathrm{R}$ & NCT03042143 (UK) \\
\hline $20(4-80)$ & $\begin{array}{c}\text { NK + UC-MSCs } \\
\text { (details not specified) }\end{array}$ & NR & ChiCTR2000030944 (China) \\
\hline $60(\geq 18)$ & $\begin{array}{c}\text { UCB-NK }+ \text { UCB-MSC } \\
3 \text { doses: } 5 \times \text { IV }\left(5 \times 10^{9}+5 \times 10^{9} \text { every } 2 \text { days }\right) \text { and } 3 \times \mathrm{IV} \\
\left(3 \times 10^{9} \mathrm{NK}+3 \times 10^{9} \mathrm{MSC} \text { every } 2 \text { days }\right) \text {, and } 1 \mathrm{IV} \\
\left(3 \times 10^{9} \mathrm{NK}+3 \times 10^{9} \text { MSC in a week }\right)\end{array}$ & NR & ChiCTR2000029817 (China) \\
\hline $600(18-90)$ & $\begin{array}{l}\text { Convalescent plasma, mesenchymal stem cell therapy, remdesivir, } \\
\text { and Tocilizumab, alone or in combination } \\
\text { IV }\left(2 \text { doses: }\left[100 \times 10^{6} \text { cells }\right] \text { and }\left[200 \times 10^{6} \text { cells }\right] \text { at } \mathrm{d} 1,4\right)\end{array}$ & NR & NCT04492501 (Pakistan) \\
\hline $86(\geq 18)$ & $\begin{array}{l}\text { Human placental hematopoietic stem cell-derived NK cells (CYNK-001) } \\
\text { IV (at days } 1,4,7 \text {; details not specified) }\end{array}$ & $\mathrm{R}$ & NCT04365101 (USA) \\
\hline $146(\geq 18)$ & $\begin{array}{l}\text { Autologous nonhematopoietic peripheral blood stem cells (NHPBSC) } \\
\text { (details not specified) }\end{array}$ & NR & $\begin{array}{l}\text { NCT04473170 (United Arab } \\
\text { Emirates) }\end{array}$ \\
\hline $30(18-75)$ & $\begin{array}{c}\text { Cryopreserved allogeneic P_MMSCs and UC-MMSCs } \\
3 \times \operatorname{IV~}\left(1 \times 10^{6} \text { cells/kg/time, once every } 3 \text { days at days } 1,4 \text {, and } 7\right)\end{array}$ & $\mathrm{R}$ & NCT04461925 (Ukraine) \\
\hline $40(18-70)$ & Allogenic pooled olfactory mucosa-derived MSCs (details not specified) & $\mathrm{E}$ & NCT04382547 (Belarus) \\
\hline $63(1-99)$ & $\begin{array}{l}\text { Hu menstrual blood SC }+ \text { artificial liver } \\
\text { IV (details not specified) }\end{array}$ & $\mathrm{R}$ & ChiCTR2000029606 (China) \\
\hline $20(18-80)$ & $\begin{array}{c}\text { ESC-derived M cells (CAStem) } \\
2 \times \text { IV }\left(3 \times 10^{6} \text { cells } / \mathrm{kg} \text {. The interval between each infusion was }\right. \\
1 \text { week ( } \pm 2 \text { days }) . \text { Second infusion at day } 7 \text { according to physician discretion.) }\end{array}$ & $\mathrm{R}$ & ChiCTR2000031139 (China) \\
\hline
\end{tabular}

$N$ : number of patients, S: status, R: recruiting, NR: not recruiting, NS; normal saline, IV: intravenous injection, NS: normal saline, MSCs: mesenchymal stem cells, UC: umbilical cord, WJ: Wharton jelly, BM: bone marrow, Ad: adipose, Dp: dental pulp, NK: natural killer cell, MSC-EVs: MSC-derived extracellular vesicles, UCB: umbilical cord blood, MNC: mononuclear cells, CM: conditioned medium.

infections of the lung has recently been tested in several animal and human models. Escherichia coli-mediated severe pneumonia in ex vivo models of human lung injury [24], influenza-induced lung injury in pig models [25], and bacterial sepsis in murine models $[26,27]$ was successfully cured by using MSC-EV or MSC-conditioned medium. In a recent study, it has been shown that conditioned medium produced by adipose-derived MSCs (ad-MSCs) could significantly reduce lung injury in murine models. The increased alveolar fluid clearance, prevention of lung from fibrosis, and improving the lung function were of the reported effect of MSC-EV on lung injury [28-30]. It is suggested that the macromolecules present in the secretome of MSCs are primarily responsible for the immunomodulatory and regenerative effects of MSCs. MSC-EVs have been applied for the management of the COVID-19 pandemic and registered in five clinical trials. The route of administration is EV infusion or EV inhalation. Recently, a trial was performed on 24 COVID-19 patients utilizing EV infusion for the treatment of COVID-19 pneumonia [31]. After a follow-up period of 14 days, the safety of MSC-EVs was approved, and no severe adverse effect was documented. The clinical signs were improved by approximately $80 \%$ of patients. Although this study included a small population and the efficacy of EV therapy could not be concluded just from this report, the potential therapeutic effects of EVs on COVID-19-induced lung injuries should be taken into account. Regarding the safety challenges of cell therapy, EVs seem to be much safer than their parent cells $[32,33]$. EVs can readily diffuse through tissues and cell barriers regarding their nanodiameter [33]. There is evidence to suggest that MSC-mediated immunomodulatory and regenerative properties are due to the vesicles originating from them.

2.4. General and Unique Properties of MSCs. Mesenchymal stromal stem cells are a heterogeneous population of cells mostly derived from two natural stem cell sources: embryonic stem cells (ESCs) and adult stem cells [34]. Adult stem cell sources such as the Wharton jelly, umbilical cord, placenta, bone marrow, adipose tissue, and dental pulp have more advantages than ESCs, considering ethical problems and risk of tumorigenesis $[34,35]$. Umbilical cord is of the most common, safe, and reliable sources of stem cell. The similarity of their gene expression profile to embryonic stem 
cells and no sign of tumorigenicity is an advantage of umbilical cord MSCs compared to ESCs [36].

MSCs are multipotent cells, known for their unique potential to regenerate damaged cells and their immunomodulatory properties $[4,37]$. They can secrete a broad range of cytokines and growth factors as soluble factors or extracellular vesicles in their condition medium. Previous studies have shown that MSCs are promising for the treatment of inflammatory or autoimmune diseases [38]. It seems that the palliative effect of MSCs on inflammatory diseases is due to their secretion profile of immunomodulatory proteins [39], although this profile can vary according to cell source and cell passage number $[5,40]$. Stem cells have other unique characteristics that make them a hopeful candidate for COVID-19 treatment. Low expression of major histocompatibility complex (MHC) makes stem cells nonimmunogenic in host patients [41]. MSCs do not express ACE2 and TMPRSS2 receptors (the virus entry gate into the host cell), a beneficial point for COVID-19 treatment [42]. The lack of these receptors on MSCs suggests that the COVID-19 virus is not able enter MSCs and infect them. MSCs can communicate with host immune cells both by cell-cell-mediated communication and by secreting soluble factors and microvesicles [43]. Recent studies have shown that the therapeutic effect of MSCs in lung injury can be due to the secretion of factors such as nitric oxide (NO), transforming growth factor- $\beta$ (TGF- $\beta$ ), prostaglandin E2 (PGE2), indoleamine2,3dioxygenase (IDO), KGF, and Ang1 [27, 44]. PGE2 induces the reprogramming of alveolar macrophages from the M1 phenotype to the alternative M2 phenotype that can release IL-10 and promote the resolution of inflammation $[45,46]$. PGE2 can also inhibit $\mathrm{T}$ cell-dependent inflammation. NO, IDO, and TGF- $\beta$ are the other factors that can suppress $\mathrm{T}$ cell-dependent inflammation [47-49]. KGF as a cytoprotective factor and Ang1 as an antipermeability agent play a pivotal role in cell regeneration of damaged lung tissue [27].

Stem cells can also downregulate the production of interferon- $\gamma$ (IFN- $\gamma$ ), TNF- $\alpha$, and IL-17 and upregulate the production of IL-10 that results in modulation of host immune response. MSCs can suppress $\mathrm{CD} 8^{+}$cells and natural killer (NK) cells as well, which leads to the inhibition of T cellmediated damage to the lung parenchyma [27, 44]. MSCs release fibrinolytic factors that might be useful for the elimination of pulmonary fibrosis [50]. MSCs can regulate the immune system by activating or suppressing the immune system (according to the around stimuli) $[4,37]$. It should be noted that the effect of modulating the immune system of mesenchymal stem cells is not long-lasting and disappears between six months to one year; however, due to the nonchronic nature of COVID-19, even the effect of temporarily modulating the MSC on the immune system can significantly help COVID-19 patients. [51].

\subsection{The Most Recent Reports Available on COVID-19 Cell} Therapies. In this section, the most recent reports on the completed trials of COVID-19 cell therapies are provided. The primary results are indicative of the safety and efficacy of MSCs therapy of COVID-19.
ChiCTR2000029990: Leng et al. were the first to report the successfulness of a pilot study on COVID-19 MSCs therapy. They reported that intravenous injection of MSCs into 7 patients infected with COVID-19 revealed encouraging outcomes and improved the clinical signs of patients. Lymphopenia, fever, shortness of breath, respiratory rate, and pneumonia infiltration were significantly recovered in these patients, and no adverse effect was reported. $\mathrm{CXCR}_{3}{ }^{+} \mathrm{CD}_{4}^{+}$ $\mathrm{T}$ cells, $\mathrm{CXCR}_{3}{ }^{+} \mathrm{CD}_{8}{ }^{+} \mathrm{T}$ cells, and $\mathrm{CXCR}_{3}{ }^{+} \mathrm{CD}_{4}{ }^{+} \mathrm{NK}$ cells disappeared after 3-6 days of MSC injection. The decreased amount of TNF- $\alpha$ and increased level of IL-10 were also observed in the treated patients [42].

NCT04252118: In this clinical study, intravenous injection of UC-MSCs $\left(3 \times 10^{7}\right.$ cells per infusion) was used for 18 enrolled COVID-19 patients, and clinical outcomes were recorded on days 0,3 , and 6 . No serious infusion-associated complication was observed, and all patients were recovered. The results of this study showed that UC-MSC IV was safe and well tolerated in patients with moderate and severe COVID-19 [52].

NCT04269525: The safety and feasibility of UC-MSC transplantation in COVID-19 were evaluated in this trial on sixteen patients with severe and critically severe conditions. No allergic reaction and adverse events were observed until 28 days after transplantation. The mortality rate decreased significantly, and oxygenation index, cytokine levels, radiological images, and lymphocyte count were improved. This study also confirmed the safety and feasibility of IV of UC-MSCs in severe cases of COVID19 pneumonia [53].

NCT04355728: This study was a phase $1 / 2$ a clinical trial which was held on 24 subjects (12 per group) in Miami, Florida, USA. Participants of each group were intravenously injected with $100 \times 10^{6} \mathrm{UC}-\mathrm{MSC}$, or vehicle, at days 0 and 3. Twenty-eight days follow-up showed that mortality rate and time of recovery were decreased significantly in the UC-MSC group compared to the control one. Besides, no serious adverse events were recorded [54].

NCT04428801: Ad-MSCs were applied in this study as one of the other MSC sources for COVID-19 stem cell therapy. The safety and prophylactic efficacy of Ad-MSCs were evaluated in a Phase II study held by Celltex (TX, USA; http://www.celltexbank.com) [55]. In this study, 200 patients were enrolled from which 100 patients were intravenously injected with autologous Ad-MSCs and 100 with placebo treatments. This cell product received FDA approval as a prophylactic against COVID-19, and the study is still recruiting.

ChiCTR2000030261: This pilot study focused on MSCderived exosomes for the treatment of seven patients with COVID-19 pneumonia. Exosomes secreted by MSCs were purified using multiple ultrafiltration and administered as a respiratory spray. The results of this study showed that aerosol inhalation of MSC-EV was not associated with any allergic reaction; besides, it improved the pulmonary lesions in COVID-19 patients. This study confirmed the safety and efficiency of nebulization of MSC-EV. The simple method used for the production of this substrate was also a beneficial point for this strategy [56]. 
According to the above-mentioned reports, MSCs and MSC-EVs are interesting and hopeful candidates for COVID-19 treatments. Although there are many other studies recruiting, it seems that MSC therapy is suitable for severe and critically severe COVID-19 patients.

2.6. The Molecular Aspects of MSCs against COVID-19: How Stem Cells Can Be Preventive against COVID-19? The cellular immune response varies in differentiated and stem cells in certain aspects. IFN production is the most common response of differentiated cells to viral infection [57]. When viruses enter the host cell, stimulate IFN production, and subsequently trigger the transcription of a wide range of interferon-stimulating genes (ISGs) in various levels based on the cell type [57], this is the main pathway for the induction of viral defense in differentiated cells and is called the innate immune response. SARS-CoV-2 virus appears to exert its effect by inhibiting IFN production in human cells [57]. Impairment of innate immune response extends SARSCoV-2 virus incubation time (2-14 days) and allows virus replication to high titration. Providing an immunesupportive agent seems to help inhibit from COVID-19 infection, particularly at the early stages of the disease. Stem cells have distinct characteristics that make them resistant to viral infections [58]. It has been shown that stem cells express ISGs continuously even in the absence of viral infection [59]. The IFN-independent ISGs expression is the basis of stem cells' intrinsic viral resistance [59]. Many studies have confirmed the resistance of pluri/multipotent cells against different pathogenic infections $[60,61]$. In contrast, differentiated cells are readily infected with viruses [62]. One of the important aspects of stem cells is that they do not generate type-I IFN in response to pathogens and are refractory to extrinsic IFNs $[63,64]$. So, it is suggested that canonical IFN signaling is not the main pathway for viral resistance in stem cells [58]. In other words, stem cells utilize an IFNindependent arrangement which is based on ISG protein expression to defend against the virus. This characteristic of stem cells can be considered a feature that is effective against COVID-19. Considering the property of SARS-CoV-2 virus for IFN shut down in infected cells, it can be suggested that stem cells can be utilized as a supportive source of cells for enhancing the innate immune response to this virus specifically at the early phase of infection. Recently, it has been shown that ISG expression can stop virus replication at the initial stages of the virus life cycle [65]. In a study by $\mathrm{Wu}$ et al., ISGs expression was analyzed in 3 germ layer-specific stem cells [58]. According to their report, mesenchymal stem cells express higher numbers of ISGs compared with pancreatic stem cells and neural stem cells [58]. Although ISG expression pattern is distinct to each type of stem cell, the family gene of IFITM was expressed at high levels in all 3 cell types [58]. IFITM genes are a component of ISGs that inhibit virus entrance to the cell and replication [66]. IFITM overexpression on the stem cell membrane is a unique property of stem cells to warrant their security against viruses.

Another macromolecule that has recently come to the attention of researchers is leukemia inhibitory factor (LIF). LIF is a stem cell growth factor that can counteract cytokine storms in the lungs during viral pneumonia [67]. This vital protein controls inflammation in the lungs and at the same time repairs lateral damage to small blood capillaries and alveoli. MSCs are of the well-known sources of soluble LIF [68]. Recently, LIF has been introduced as an attractive treatment option for multiple sclerosis and neurodegenerative diseases associated with inflammation since LIF has been shown to repair damaged neurons in the brain and spinal cord of the central nervous system [69]. One of the important clinical features of LIF is that it can directly inhibit IL-6 activity, thereby preventing cytokine storms [70]. Targeting the IL-6 pathway is an interesting clinical approach to reduce COVID-19 mortality. The use of tocilizumab human monoclonal antibody to bind and block IL-6 receptors is one of these studies [71]. LIF is suggested to be used not only as a therapeutic option but also as a protective agent against the pathogenesis of COVID-19 progression. It has been shown that the LIF/IL-6 axis can correct the inflammatory response of the host and not only protects the lungs against chronic diseases but also speeds up the regeneration of other organs after COVID-19 is eliminated, although there exists a challenge associated with the burden cost of providing sufficient LIF for treatment. Recently, using nanotechnology synthetic stem cells, a product called "LIFNano" has been invented that has shown a thousand times more power than soluble LIF [72]. In an animal study, treatment with LIFNano was performed on a preclinical model of multiple sclerosis (MS), and the result was cured paralysis within 4 days [72]. This short time frame for clinical outcomes is consistent with reporting the beneficial effects of MSC treatment on COVID-19 pneumonia. LIFNano is a newly emerging alternative to cell-based therapy that can regenerate damaged tissues and suppress cytokine storms in pneumonia by providing nanoparticles of active LIF that are a thousand times more potent than soluble LIF. LIF seems to be able to reduce the severity of the disease and thus reduce the pressure on global health systems. The suggested routes of administration are direct delivery of LIF to the respiratory system (nasal inhalation) or intravenous injection [70, 73, 74].

Besides the molecular aspects mentioned above, there is a huge bulk of studies which indicate the protective ability of MSC against the inflammation-induced damage of pulmonary endothelial cells and alveolar epithelial cell. The secretome of MSCs is composed of several cell-protective bioagents each of which is of a pivotal role in the protection and restoration of impaired alveolar cells [13, 75]. Ang1, PGE2, HGF, and KGF are the protective factors secreted by MSCs that inhibit alveolar cells from inflammation and oxidative damages $[10,76,77]$. Studies in animal models of ARDS have shown that MSCs can upregulate the level of metalloproteinase- (MMP-) 8 and downregulate the expression of tissue inhibitor of metalloproteinase- (TIMP-) 1, IL$1 \beta$, and TGF- $\beta 1$ to attenuate the lung fibrosis $[78,79]$.

Finally, we want to hypothesize that more functional stem cells in the body might be able to prevent COVID-19 infection or decrease the symptoms by increasing the ability to repair, protecting the lung cells, and immunomodulatory properties. An evidence-based observation is the lower rate of contagion, milder symptoms, and a lower rate of mortality 
of COVID-19 in younger patients [80, 81]. Reports are indicating that although people of all ages can be infected by this virus, the disease progresses faster and shows more severe symptoms in the elderly than in the young [82]. This might be directly related to the aging-associated dysfunction of stem cells in the elderly [83]. Perhaps the proliferating stem cells in young people are playing a defensive role against COVID-19 infection. However, the observations just provide basic evidence for the possible effect of stem cells in prevention against COVID-19, and there is still a long way to apply this modality in humans.

2.7. Can Stem Cells Be Used for COVID-19 Vaccination? Vaccination seems to be the most effective means of prevention against COVID-19 contagion. Recently, many studies have been conducted to develop the COVID-19 vaccine, and many options have been proposed, including DNA- and RNAbased engineered vaccines, but there are still limitations and warning points about the vaccines, including efficacy, tolerability, safety, and immune adaptability [84]. New approaches to vaccine development have been introduced recently, including cellular vaccine strategies which have been mostly used against cancer $[85,86]$. Cellular vaccines benefit from the direct transfer of transfected host cells for in vivo production of vaccine antigens. Mesenchymal stem cells are a newfound platform for designing genetically engineered cellular vaccines that hold the promise to produce efficient and safe vehicles for enhancing the host immune response [87]. Using human-engineered mesenchymal stem cells (hu-MSCs) to produce the SARS-CoV-2 N-protein antigen is one of the promising strategies that has been reported in a recent paper of Chinese researchers as a candidate for producing the COVID-19 vaccine [88]. They showed that mesenchymal stem cells engineered to produce COVID-19 proteins could provide a new bench for effective vaccine development. In this proof of concept study, transfected allogeneic mesenchymal stem cells (carrying plasmids for SARS-CoV-2 N-protein) were applied for mice injection. Twenty days after intramuscularly or subcutaneously vaccination, blood samples from the mice were tested for detection of antibodies against $\mathrm{N}$-protein using enzyme-linked immunosorbent assay (ELISA). The results of this study demonstrated that one dose of vaccination led to positive antibody production in the serum of injected mice. Moreover, the MSCs carrying the transfected gene are cleared from the bloodstream by the immune system 20 days after injection.

To be more successful in using engineered mesenchymal cells as vaccines, MSCs must be as invisible to the recipient's immune system as possible [89]. In a recent study, human mesenchymal stem cells were genetically engineered using the MSCVneo retrovirus so that HLA-1 expression was downregulated [90]. Subsequent studies showed that the injection of these stem cells was associated with a decrease in the proliferation of mononuclear cells in animal models and human subjects [90]. Future directions in this field may include strategies to modify the transfected proteins in the stem cells by posttranslational processes such as acetylation and glycosylation. In this way, the engineered antigen becomes more like viral proteins in vivo, can simulate the host immune response much better, and increase the success rate of immune protection.

2.8. Challenges to Use MSCs. Although clinical observations indicate the high potential of MSCs in the treatment of fatal diseases such as COVID-19, there are still several issues associated with the administration of MSCs. The heterogeneous source of MSCs, methods of preparation, number of MSCs, and the age of the cell population can certainly lead to various functional differences. This variation might be in the potential of cytokine release, cytokine content, and the therapeutic capacity [27]. Even the variation in size, shape, and passage number of MSCs or MSC-EVs may also lead to different therapeutic effects of this biological substrate. In a study by Kowal et al., it has been shown that different sizes of EVs derived from dendritic cells can exert different effects on $\mathrm{T}$ cells [91]. The cost and speed of sample preparation are also issues that should be taken into consideration. Although MSC-EVs seem to be much cheaper and easier to largescale production compared to their cells of origin. Another requirement for MSC therapeutic application is a wellestablished protocol that fulfills the criteria of Good Manufacturing Practice (GMP) for the production of clinical-grade MSCs [92]. Moreover, standard methods are required for producing MSCs or MSC-EVs in a high degree of purity appropriate for use at the industrial level. The produced MSCs for therapeutic applications should be evaluated considering the criteria recommended by the international society for cell therapy (ISCT). The presence of certain surface markers, analysis of protein content, secretome, MSCEVs, and microRNAs should be approved by using standard assays before any therapeutic applications $[93,94]$. It seems that a reliable cell bank for production, quality control, and storage of standard MSC vials might compensate for these challenges in an emergency condition.

Another main challenge of using MSCs therapy for COVID-19 patients is that COVID-19-infected patients are at the risk of hypercoagulation [95]. MSCs have been shown to possess procoagulation properties. Recently, Moll et al. have nicely provided the safety hazards and applicable protocols for the preparation of MSCs to overcome this problem [96]. It is strongly recommended that well-characterized cell products, checked for rare expression of tissue factor (TF/CD142) on their surface, be used for clinical application. Also, consideration of nonintravascular routes of MSC or MSC-EV administration is encouraged to reduce the risk and improve the safety and efficacy of COVID-19 cell therapy.

\section{Conclusion}

According to recent reports, MSC-based treatments seem to be an innovative biological intervention for the treatment of COVID-19. Considering the exclusivity of MSCs to defend against viruses, immunomodulatory properties, and their potential for tissue regeneration, MSC-based treatments deserve more attention from researchers and seem to be applied more to treat COVID-19. However, there are several challenges associated with cell-based therapies. Perhaps, 
using a standard and creative approach to stem cell utilization can solve previous challenges.

\section{Abbreviation}

\begin{tabular}{|c|c|}
\hline Ang1: & Angiopoietin-1 \\
\hline ARDS: & Acute respiratory distress syndrome \\
\hline ESCs: & Embryonic stem cells \\
\hline EVs: & Extracellular vesicles \\
\hline GMP: & Good manufacturing practice \\
\hline GSCF: & Granulocyte colony-stimulating factor \\
\hline ICTRP: & $\begin{array}{l}\text { International Clinical Trials Registry } \\
\text { Platform }\end{array}$ \\
\hline IDO: & Indoleamine2,3-dioxygenase \\
\hline IFN: & Interferon \\
\hline IL: & Interleukin \\
\hline IP10: & Interferon-inducible protein 10 \\
\hline ISCT: & International Society for Cell Therapy \\
\hline ISGs: & Interferon-stimulating genes \\
\hline IV: & Intravenous injection \\
\hline KGF: & Keratinocyte growth factor \\
\hline MCP1: & Monocyte chemotactic protein 1 \\
\hline MHC: & Major histocompatibility complex \\
\hline MIP1A: & Macrophage inflammatory protein $1 \mathrm{~A}$ \\
\hline MSCs: & Mesenchymal stem cells \\
\hline NK cell: & Natural killer cell \\
\hline NO: & Nitric oxide \\
\hline PGE2: & Prostaglandin E2 \\
\hline SARS-CoV-2: & $\begin{array}{l}\text { Severe acute respiratory syndrome coronavi- } \\
\text { rus } 2\end{array}$ \\
\hline TGF- $\beta$ : & Transforming growth factor- $\beta$ \\
\hline TNF- $\alpha$ : & Tumor necrosis factor- $\alpha$ \\
\hline WHO: & World Health Organization. \\
\hline
\end{tabular}

\section{Conflicts of Interest}

The authors declare that they have no conflict of interest.

\section{Authors' Contributions}

M. A and F. S-J were involved in conception and design of the study, acquisition of documents, interpretation of available studies, drafting the manuscript, and final revision.

\section{Acknowledgments}

The authors would like to thank the directors of Shiraz University of Medical Sciences for supporting this research. All authors have read the journal's policy on disclosure of potential conflicts of interest and a statement that all authors have disclosed any financial or personal relationship with organizations that could potentially be perceived as influencing the described research.

\section{References}

[1] N. Satija and S. K. Lal, "The molecular biology of SARS coronavirus," Annals of the New York Academy of Sciences., vol. 1102, no. 1, pp. 26-38, 2007.
[2] M. Lotfi and N. Rezaei, "SARS-CoV-2: a comprehensive review from pathogenicity of the virus to clinical consequences," Journal of Medical Virology., vol. 92, no. 10, pp. 1864-1874, 2020.

[3] M. Cascella, M. Rajnik, A. Cuomo, S. C. Dulebohn, and R. Di Napoli, Features, evaluation and treatment coronavirus (COVID-19), Statpearls: StatPearls Publishing, 2020.

[4] P. Mallis, E. Michalopoulos, T. Chatzistamatiou, and C. Stavropoulos-Giokas, "Mesenchymal stromal cells as potential immunomodulatory players in severe acute respiratory distress syndrome induced by SARS-CoV-2 infection," World Journal of Stem Cells., vol. 12, no. 8, pp. 731-751, 2020.

[5] V. Börger, D. J. Weiss, J. D. Anderson et al., "International Society for Extracellular Vesicles and International Society for Cell and Gene Therapy statement on extracellular vesicles from mesenchymal stromal cells and other cells: considerations for potential therapeutic agents to suppress coronavirus disease-19," Cytotherapy, vol. 22, no. 9, pp. 482-485, 2020

[6] W. Zhang, Y. Zhao, F. Zhang et al., "The use of antiinflammatory drugs in the treatment of people with severe coronavirus disease 2019 (COVID-19): The Perspectives of clinical immunologists from China," Clinical Immunology, vol. 214, p. 108393, 2020.

[7] A. P. H. Karlsen, S. Wiberg, J. Laigaard, C. Pedersen, K. Z. Rokamp, and O. Mathiesen, "A systematic review of trial registry entries for randomized clinical trials investigating COVID-19 medical prevention and treatment," PLoS One, vol. 15, no. 8, article e0237903, 2020.

[8] H. Yagi, A. Soto-Gutierrez, B. Parekkadan et al., "Mesenchymal stem cells: mechanisms of immunomodulation and homing," Cell transplantation., vol. 19, no. 6-7, pp. 667-679, 2010.

[9] K. Le Blanc and D. Mougiakakos, "Multipotent mesenchymal stromal cells and the innate immune system," Nature Reviews Immunology., vol. 12, no. 5, pp. 383-396, 2012.

[10] O. Bernard, F. Jeny, Y. Uzunhan et al., "Mesenchymal stem cells reduce hypoxia-induced apoptosis in alveolar epithelial cells by modulating HIF and ROS hypoxic signaling," American Journal of Physiology-Lung Cellular and Molecular Physiology, vol. 314, no. 3, pp. L360-LL71, 2018.

[11] X. X. T. L. Chen, Z. H. Han, W. J. Wang, and J. G. Meng, "Coculture with bone marrow-derived mesenchymal stem cells attenuates inflammation and apoptosis in lipopolysaccharide-stimulated alveolar epithelial cells via enhanced secretion of keratinocyte growth factor and angiopoietin-1 modulating the Toll-like receptor-4 signal pathway," Molecular Medicine Reports, vol. 19, no. 3, pp. 1891-1902, 2019.

[12] S. S. Meng, F. M. Guo, X. W. Zhang et al., "mTOR/STAT-3 pathway mediates mesenchymal stem cell-secreted hepatocyte growth factor protective effects against lipopolysaccharideinduced vascular endothelial barrier dysfunction and apoptosis," Journal of Cellular Biochemistry, vol. 120, no. 3, pp. 3637-3650, 2019.

[13] H. Qin and A. Zhao, "Mesenchymal stem cell therapy for acute respiratory distress syndrome: from basic to clinics," Protein \& cell., vol. 11, no. 10, pp. 707-722, 2020.

[14] M. Diamond, H. L. P. Feliciano, D. Sanghavi, and S. Mahapatra, Acute respiratory distress syndrome (ARDS), StatPearls, 2020.

[15] E. Schmelzer, V. Miceli, C. M. Chinnici, A. Bertani, and J. C. Gerlach, "Effects of mesenchymal stem cell coculture on 
human lung small airway epithelial cells," BioMed research international., vol. 2020, pp. 1-8, 2020.

[16] Y. Han, J. Ren, Y. Bai, X. Pei, and Y. Han, "Exosomes from hypoxia-treated human adipose-derived mesenchymal stem cells enhance angiogenesis through VEGF/VEGF-R," The international journal of biochemistry \& cell biology., vol. 109, pp. 59-68, 2019.

[17] H. Lv, Q. Liu, Y. Sun et al., "Mesenchymal stromal cells ameliorate acute lung injury induced by LPS mainly through stanniocalcin-2 mediating macrophage polarization," Annals of Translational Medicine, vol. 8, no. 6, p. 334, 2020.

[18] M. A. Matthay, "Therapeutic potential of mesenchymal stromal cells for acute respiratory distress syndrome," Annals of the American Thoracic Society, vol. 12, Supplement 1, pp. S54-S57, 2015.

[19] J. G. Laffey and M. A. Matthay, "Fifty years of research in ARDS. Cell-based therapy for acute respiratory distress syndrome. Biology and potential therapeutic value," American journal of respiratory and critical care medicine., vol. 196, no. 3, pp. 266-273, 2017.

[20] M. A. Matthay, A. Goolaerts, J. P. Howard, and J. W. Lee, "Mesenchymal stem cells for acute lung injury: preclinical evidence," Critical care medicine, vol. 38, 10 Suppl, pp. S569S573, 2010.

[21] A. H. Mansourabadi, M. Sadeghalvad, H.-R. MohammadiMotlagh, and N. Rezaei, "The immune system as a target for therapy of SARS-CoV-2: a systematic review of the current immunotherapies for COVID-19," Life sciences, vol. 258, p. 118185, 2020.

[22] J. Kowal, M. Tkach, and C. Théry, "Biogenesis and secretion of exosomes," Current opinion in cell biology., vol. 29, pp. 116$125,2014$.

[23] A. V. Vlassov, S. Magdaleno, R. Setterquist, and R. Conrad, "Exosomes: current knowledge of their composition, biological functions, and diagnostic and therapeutic potentials," Biochimica et Biophysica Acta (BBA)-General Subjects, vol. 1820, no. 7, pp. 940-948, 2012.

[24] J. Park, S. Kim, H. Lim et al., "Therapeutic effects of human mesenchymal stem cell microvesicles in an ex vivo perfused human lung injured with severe E. coli pneumonia," Thorax, vol. 74, no. 1, pp. 43-50, 2019.

[25] M. Khatri, L. A. Richardson, and T. Meulia, "Mesenchymal stem cell-derived extracellular vesicles attenuate influenza virus-induced acute lung injury in a pig model," Stem cell research \& therapy, vol. 9, no. 1, p. 17, 2018.

[26] S. Wecht and M. Rojas, "Mesenchymal stem cells in the treatment of chronic lung disease," Respirology, vol. 21, no. 8, pp. 1366-1375, 2016.

[27] M. Muraca, A. Pessina, M. Pozzobon et al., "Mesenchymal stromal cells and their secreted extracellular vesicles as therapeutic tools for COVID-19 pneumonia?," Journal of Controlled Release, vol. 325, pp. 135-140, 2020.

[28] S. Gennai, A. Monsel, Q. Hao, J. Park, M. Matthay, and J. Lee, "Microvesicles derived from human mesenchymal stem cells restore alveolar fluid clearance in human lungs rejected for transplantation," American Journal of Transplantation, vol. 15, no. 9, pp. 2404-2412, 2015.

[29] A. Cargnoni, L. Gibelli, A. Tosini et al., "Transplantation of allogeneic and xenogeneic placenta-derived cells reduces bleomycin-induced lung fibrosis," Cell transplantation., vol. 18, no. 4, pp. 405-422, 2009.
[30] N. Mansouri, G. R. Willis, A. Fernandez-Gonzalez et al., "Mesenchymal stromal cell exosomes prevent and revert experimental pulmonary fibrosis through modulation of monocyte phenotypes," JCI insight, vol. 4, no. 21, 2019.

[31] V. Sengupta, S. Sengupta, A. Lazo, P. Woods, A. Nolan, and N. Bremer, "Exosomes derived from bone marrow mesenchymal stem cells as treatment for severe COVID-19," Stem Cells and Development, vol. 29, no. 12, pp. 747-754, 2020.

[32] M. Muraca, M. Piccoli, C. Franzin et al., "Diverging concepts and novel perspectives in regenerative medicine," International journal of molecular sciences., vol. 18, no. 5, p. 1021, 2017.

[33] H. Xin, Y. Li, Y. Cui, J. J. Yang, Z. G. Zhang, and M. Chopp, "Systemic administration of exosomes released from mesenchymal stromal cells promote functional recovery and neurovascular plasticity after stroke in rats," Journal of Cerebral Blood Flow \& Metabolism., vol. 33, no. 11, pp. 1711-1715, 2013.

[34] M. Dominici, P. Paolucci, P. Conte, and E. M. Horwitz, "Heterogeneity of multipotent mesenchymal stromal cells: from stromal cells to stem cells and vice versa," Transplantation, vol. 87, no. 9S, pp. S36-S42, 2009.

[35] D. G. Phinney, "Functional heterogeneity of mesenchymal stem cells: implications for cell therapy," Journal of Cellular Biochemistry, vol. 113, no. 9, pp. 2806-2812, 2012.

[36] T. Nagamura-Inoue and H. He, "Umbilical cord-derived mesenchymal stem cells: their advantages and potential clinical utility," World journal of stem cells., vol. 6, no. 2, pp. 195202, 2014.

[37] H. K. Salem and C. Thiemermann, "Mesenchymal stromal cells: current understanding and clinical status," Stem Cells, vol. 28, no. 3, pp. 585-596, 2010.

[38] S. Regmi, S. Pathak, J. O. Kim, C. S. Yong, and J.-H. Jeong, "Mesenchymal stem cell therapy for the treatment of inflammatory diseases: challenges, opportunities, and future perspectives," European journal of cell biology., vol. 98, no. 5-8, p. 151041, 2019.

[39] Y. Shi, Y. Wang, Q. Li et al., "Immunoregulatory mechanisms of mesenchymal stem and stromal cells in inflammatory diseases," Nature Reviews Nephrology., vol. 14, no. 8, pp. 493507, 2018.

[40] F. Gao, S. M. Chiu, D. A. L. Motan et al., "Mesenchymal stem cells and immunomodulation: current status and future prospects," Cell death \& disease, vol. 7, no. 1, p. e2062, 2016.

[41] J. Walter, L. B. Ware, and M. A. Matthay, "Mesenchymal stem cells: mechanisms of potential therapeutic benefit in ARDS and sepsis," The Lancet Respiratory Medicine., vol. 2, no. 12, pp. 1016-1026, 2014.

[42] Z. Leng, R. Zhu, W. Hou et al., "Transplantation of ACE2mesenchymal stem cells improves the outcome of patients with COVID-19 pneumonia," Aging and disease., vol. 11, no. 2, pp. 216-228, 2020.

[43] M. E. Bernardo and W. E. Fibbe, "Mesenchymal stromal cells: sensors and switchers of inflammation," Cell Stem Cell, vol. 13, no. 4, pp. 392-402, 2013.

[44] V. Rao, S. Thakur, J. Rao et al., "Mesenchymal stem cellsbridge catalyst between innate and adaptive immunity in COVID 19," Medical Hypotheses, vol. 143, p. 109845, 2020.

[45] K. Németh, A. Leelahavanichkul, P. S. T. Yuen et al., "Bone marrow stromal cells attenuate sepsis via prostaglandin $\mathrm{E}_{2}$ dependent reprogramming of host macrophages to increase 
their interleukin-10 production," Nature medicine, vol. 15, no. 1, pp. 42-49, 2009.

[46] S. Herold, K. Mayer, and J. Lohmeyer, "Acute lung injury: how macrophages orchestrate resolution of inflammation and tissue repair," Frontiers in immunology, vol. 2, 2011.

[47] M. Wang, Q. Yuan, and L. Xie, "Mesenchymal stem cell-based immunomodulation: properties and clinical application," Stem cells international., vol. 2018, pp. 1-12, 2018.

[48] K. English, J. Ryan, L. Tobin, M. Murphy, F. P. Barry, and B. P. Mahon, "Cell contact, prostaglandin E2 and transforming growth factor beta 1 play non-redundant roles in human mesenchymal stem cell induction of CD4+ CD25Highforkhead box P3+ regulatory T cells," Clinical \& Experimental Immunology, vol. 156, no. 1, pp. 149-160, 2009.

[49] O. K.-F. Ma and K. H. Chan, "Immunomodulation by mesenchymal stem cells: interplay between mesenchymal stem cells and regulatory lymphocytes," World journal of stem cells., vol. 8, no. 9, pp. 268-278, 2016.

[50] B. Heissig, Y. Salama, S. Takahashi, T. Osada, and K. Hattori, "The multifaceted role of plasminogen in inflammation," Cellular Signalling, vol. 75, p. 109761, 2020.

[51] J. Pawitan, "Prospect of stem cell therapy to avoid cytokine storm in severe covid-19," International Journal of Applied Pharmaceutics, vol. 12, no. 5, 2020.

[52] F. Meng, R. Xu, S. Wang et al., "Human umbilical cord-derived mesenchymal stem cell therapy in patients with COVID-19: a phase 1 clinical trial," Signal transduction and targeted therapy, vol. 5, no. 1, p. 172, 2020.

[53] Y. Feng, J. Huang, J. Wu et al., "Safety and feasibility of umbilical cord mesenchymal stem cells in patients with COVID-19 pneumonia: a pilot study," Cell Proliferation, vol. 53, no. 12, p. e12947, 2020.

[54] G. Lanzoni, E. Linetsky, D. Correa et al., "Umbilical cord mesenchymal stem cells for COVID-19 ARDS: a double blind, phase 1/2a, randomized controlled trial," STEM CELLS Translational Medicine, 2020.

[55] D. Ilic and M. Liovic, "Industry updates from the field of stem cell research and regenerative medicine in June 2020," Regenerative Medicine., vol. 15, no. 10, pp. 2145-2152, 2020.

[56] M. Chu, H. Wang, L. Bian et al., Nebulization therapy for COVID-19 pneumonia with embryonic mesenchymal stem cells-derived exosomes, 2020.

[57] D. E. Levy, I. J. Marié, and J. E. Durbin, "Induction and function of type I and III interferon in response to viral infection," Current opinion in virology., vol. 1, no. 6, pp. 476-486, 2011.

[58] X. Wu, V. L. D. Thi, Y. Huang et al., "Intrinsic immunity shapes viral resistance of stem cells," Cell, vol. 172, no. 3, pp. 423-438.e25, 2018.

[59] W. Wang, Y. Yin, L. Xu et al., "Unphosphorylated ISGF3 drives constitutive expression of interferon-stimulated genes to protect against viral infections," Science Signaling, vol. 10, no. 476, p. eaah4248, 2017.

[60] J.-P. Belzile, T. J. Stark, G. W. Yeo, and D. H. Spector, "Human cytomegalovirus infection of human embryonic stem cellderived primitive neural stem cells is restricted at several steps but leads to the persistence of viral DNA," Journal of virology., vol. 88, no. 8, pp. 4021-4039, 2014.

[61] N. Y. Villa, S. Bais, W. M. Chan et al., “_Ex vivo_virotherapy with myxoma virus does not impair hematopoietic stem and progenitor cells," Cytotherapy, vol. 18, no. 3, pp. 465-480, 2016.
[62] X. Wu, J. M. Robotham, E. Lee et al., "Productive hepatitis C virus infection of stem cell-derived hepatocytes reveals a critical transition to viral permissiveness during differentiation," PLoS Pathogens, vol. 8, no. 4, article e1002617, 2012.

[63] D. C. Burke, C. F. Graham, and J. M. Lehman, "Appearance of interferon inducibility and sensitivity during differentiation of murine teratocarcinoma cells in vitro," Cell, vol. 13, no. 2, pp. 243-248, 1978.

[64] X.-X. Hong and G. G. Carmichael, "Innate Immunity in Pluripotent Human Cells:," Journal of Biological Chemistry., vol. 288, no. 22, pp. 16196-16205, 2013.

[65] J. W. Schoggins and C. M. Rice, "Interferon-stimulated genes and their antiviral effector functions," Current opinion in virology., vol. 1, no. 6, pp. 519-525, 2011.

[66] S. Smith, S. Weston, P. Kellam, and M. Marsh, "IFITM proteins-cellular inhibitors of viral entry," Current opinion in virology., vol. 4, pp. 71-77, 2014.

[67] R. F. Foronjy, A. J. Dabo, N. Cummins, and P. Geraghty, "Leukemia inhibitory factor protects the lung during respiratory syncytial viral infection," BMC immunology., vol. 15, no. 1, p. 41, 2014.

[68] A. Nasef, C. Mazurier, S. Bouchet et al., "Leukemia inhibitory factor: role in human mesenchymal stem cells mediated immunosuppression," Cellular immunology., vol. 253, no. 12, pp. 16-22, 2008.

[69] K. Janssens, C. Van den Haute, V. Baekelandt et al., "Leukemia inhibitory factor tips the immune balance towards regulatory T cells in multiple sclerosis," Brain, behavior, and immunity, vol. 45, pp. 180-188, 2015.

[70] S. M. Metcalfe, "COVID-19 lockdown: de-risking exit by protecting the lung with leukaemia inhibitory factor (LIF)," Medicine in Drug Discovery, vol. 6, p. 100043, 2020.

[71] C. Zhang, Z. Wu, J.-W. Li, H. Zhao, and G.-Q. Wang, "Cytokine release syndrome in severe COVID-19: interleukin-6 receptor antagonist tocilizumab may be the key to reduce mortality," International journal of antimicrobial agents, vol. 55, no. 5, p. 105954, 2020.

[72] S. M. Metcalfe, T. B. Strom, A. Williams, and T. M. Fahmy, "Multiple sclerosis and the LIF/IL-6 axis: use of nanotechnology to harness the tolerogenic and reparative properties of LIF," Nanobiomedicine, vol. 2, p. 5, 2015.

[73] C. K. Maurya, R. Misra, P. Sharma et al., "Novel stem cells and nucleic acid-based vaccine trials against viral outbreak: a systematic evaluation during COVID-2019 pandemic," Indian Journal of Clinical Biochemistry, vol. 35, no. 4, pp. 397-409, 2020.

[74] S. M. Metcalfe, "Mesenchymal stem cells and management of COVID-19 pneumonia," Medicine in drug discovery, vol. 5, p. 100019, 2020.

[75] C. R. Harrell, B. P. Jovicic, V. Djonov, and V. Volarevic, “Therapeutic potential of mesenchymal stem cells and their secretome in the treatment of SARS-CoV-2-induced acute respiratory distress syndrome," Analytical cellular pathology., vol. 2020, pp. 1-11, 2020.

[76] X. Fang, A. P. Neyrinck, M. A. Matthay, and J. W. Lee, “Allogeneic human mesenchymal stem cells restore epithelial protein permeability in cultured human alveolar type II cells by secretion of angiopoietin-1," Journal of Biological Chemistry., vol. 285, no. 34, pp. 26211-26222, 2010.

[77] X. Yan, X. Fu, Y. Jia et al., "Nrf2/Keap1/ARE signaling mediated an antioxidative protection of human placental 
mesenchymal stem cells of fetal origin in alveolar epithelial cells," Oxidative medicine and cellular longevity., vol. 2019, pp. 1-12, 2019.

[78] J. D. Silva, M. Lopes-Pacheco, A. H. R. Paz et al., "Mesenchymal stem cells from bone marrow, adipose tissue, and lung tissue differentially mitigate lung and distal organ damage in experimental acute respiratory distress syndrome," Critical care medicine, vol. 46, no. 2, pp. e132-e140, 2018.

[79] T. Maron-Gutierrez, J. D. Silva, K. D. Asensi et al., "Effects of mesenchymal stem cell therapy on the time course of pulmonary remodeling depend on the etiology of lung injury in mice," Critical Care Medicine., vol. 41, no. 11, pp. e319-e333, 2013.

[80] CDC COVID-19 Response Team, S. Bialek, R. Gierke et al., "Coronavirus disease 2019 in children-United States, February 12-April 2, 2020," Morbidity and Mortality Weekly Report, vol. 69 , no. 14, 2020.

[81] X. Lu, L. Zhang, H. Du et al., "SARS-CoV-2 infection in children," New England Journal of Medicine, vol. 382, no. 17, pp. 1663-1665, 2020.

[82] P. Sun, X. Lu, C. Xu, W. Sun, and B. Pan, "Understanding of COVID-19 based on current evidence," Journal of medical virology., vol. 92, no. 6, pp. 548-551, 2020.

[83] A. S. I. Ahmed, M. H. Sheng, S. Wasnik, D. J. Baylink, and K.H. W. Lau, "Effect of aging on stem cells," World journal of experimental medicine, vol. 7, no. 1, pp. 1-10, 2017.

[84] F. Krammer, "SARS-CoV-2 vaccines in development," Nature, vol. 586, no. 7830, pp. 516-527, 2020.

[85] D. T. Le, D. M. Pardoll, and E. M. Jaffee, "Cellular vaccine approaches," The Cancer Journal, vol. 16, no. 4, 2010.

[86] C. Ren, S. Kumar, D. Chanda, J. Chen, J. D. Mountz, and S. Ponnazhagan, "Therapeutic potential of mesenchymal stem cells producing interferon- $\alpha$ in a mouse melanoma lung metastasis model," Stem Cells, vol. 26, no. 9, pp. 2332-2338, 2008.

[87] S. L. Tomchuck, E. B. Norton, R. F. Garry et al., "Mesenchymal stem cells as a novel vaccine platform," Frontiers in cellular and infection microbiology, vol. 2, 2012.

[88] J. Liu, H. Jiao, and X. Yin, "Engineered human mesenchymal stem cells as new vaccine platform for COVID-19," bioRxiv, 2020.

[89] A. K. Varkouhi, A. P. T. Monteiro, J. N. Tsoporis, S. H. Mei, D. J. Stewart, and C. C. Dos Santos, "Genetically modified mesenchymal stromal/stem cells: application in critical illness," Stem Cell Reviews and Reports, vol. 16, no. 5, pp. 812-827, 2020.

[90] M. A. Soland, M. G. Bego, E. Colletti et al., "Modulation of human mesenchymal stem cell immunogenicity through forced expression of human cytomegalovirus us proteins," PLoS One, vol. 7, no. 5, article e36163, 2012.

[91] J. Kowal, G. Arras, M. Colombo et al., "Proteomic comparison defines novel markers to characterize heterogeneous populations of extracellular vesicle subtypes," Proceedings of the National Academy of Sciences., vol. 113, no. 8, pp. E968E977, 2016.

[92] H. Lloyd-Williams and D. A. Hughes, "A systematic review of economic evaluations of advanced therapy medicinal products," British Journal of Clinical Pharmacology, 2020.

[93] M. S. Choudhery and D. T. Harris, "Stem cell therapy for COVID-19: possibilities and challenges," Cell biology international., vol. 44, no. 11, pp. 2182-2191, 2020.
[94] C. Li, H. Zhao, and B. Wang, "Challenges for mesenchymal stem cell-based therapy for COVID-19," Drug Design, Development and Therapy, vol. Volume 14, pp. 3995-4001, 2020.

[95] Y. Fei, N. Tang, H. Liu, and W. Cao, "Coagulation dysfunction," Archives of pathology \& laboratory medicine., vol. 144, no. 10, pp. 1223-1229, 2020.

[96] G. Moll, N. Drzeniek, J. Kamhieh-Milz, S. Geissler, H.-D. Volk, and P. Reinke, "MSC therapies for COVID-19: importance of patient coagulopathy, thromboprophylaxis, cell product quality and mode of delivery for treatment safety and efficacy," Frontiers in immunology., vol. 11, p. 1091, 2020. 